www.jmscr.igmpublication.org

Impact Factor 5.244

Index Copernicus Value: 5.88

ISSN (e)-2347-176x ISSN (p) 2455-0450

crossref DOI: http://dx.doi.org/10.18535/jmscr/v4i6.34

Journal Of Medical Science And Clinical Research

IGM Publication

An official Publication of IGM Publication

\title{
Infant Feeding Practices in A Well Baby Clinic of A Tertiary Hospital in North Kerala
}

\author{
Authors \\ Dr Kavitha Pavithran, Dr Anil kumar Aalinkeel, Dr Ravikumar Payora \\ Department of Pediatrics, A.C.M.E Pariyaram, Kannur. Kerala \\ Corresponding Author \\ Dr Kavitha Pavithran \\ Department of Pediatrics, A.C.M.E Pariyaram, Kannur. Kerala. 670503 \\ Email: kavashu@gmail.com Phone: 9446454969
}

\begin{abstract}
Aim and objective: To study the infant feeding practices among mothers accompanying infants in a well baby clinic. To evaluate the association between educational status and religion of mother and the feeding practice.

Methods: A clinic based cross-sectional descriptive study among mothers accompanying infants for immunization and check up during a period of six months. Data was collected using a pre tested questionnaire Results: A total of 432 mothers and their infants were enrolled in the study. $19.8 \%$ of infants were given prelacteal feeds. All the babies received colostrum. $92.5 \%$ were initiated breast feeding within one hour after delivery. $97 \%$ of the mothers practiced breast feeding on demand. 72\% of babies who were less than 6 months of age were exclusively breast fed. Among babies older than 6 months $71.6 \%$ were started on early complementary feeding and $2.1 \%$ of them were not on complementary feeding. Early initiation of breast feeding was significantly more in mothers with higher educational status. Exclusive breast feeding was less and artificial feeds usage was more in mothers with higher educational status. Religion also showed significant association with type and time of first feed.

Conclusion: Despite higher rate of early initiation of breast feeding, colostrum feeding and demand feeding, exclusive breast feeding was comparatively low. Early initiation of complementary feeding was also noted. Knowledge and practice of infant feeding varied with religion and educational status of the mother Key words colostrum, complementary feeding, exclusive breast feeding, infant feeding practices, prelacteals
\end{abstract}

\section{INTRODUCTION}

Infant feeding practices vary from place and from time to time. Breast milk has been established as the most wholesome source of nutrition, in the early months of life. It is worth noting that only humans resort to milk of other mammals for feeding their own young. Unfortunately the virtues of this practice have been extolled, duly exploited and packaged as baby food by the industry. Even members of the Medical profession have set themselves as bad examples by artificially feeding their infants. Cultural changes, industrialization, forced working mothers to modify the feeding practices. Artificial feeding and inappropriate weaning methods have come into practice. 
Breastfeeding is one of the most important determinants of child survival, birth spacing, and the prevention of childhood infections. The beneficial effects of breastfeeding depend on its initiation, duration, and the age at which the breastfed child is weaned. Breastfeeding practices vary among different regions and community ${ }^{1}$

The practice of breastfeeding among Indian mothers is almost universal, but initiation of breastfeeding is quite late and the colostrum is usually discarded. Breastfeeding practices in rural communities are shaped by their beliefs, which are influenced by social, cultural, and economic factors.

The Third National Family health survey (NFHS-

3) rates regarding breast feeding initiation was $29.4 \%, 30.3 \%$ and $64.5 \%$ at half an hour, one hour and one day respectively. Exclusive breast feeding in $<6$ months was $46.4 \%$. At 6-8 months only $50 \%$ was on complementary feeds. According to NHFS 3 results in Kerala initiation of breast feeding within a hour was $52.9 \%$ and $58.2 \%$ in the urban and rural areas respectively, $96 \%$ of mothers had started feeding within the first day itself. All the rates showed increase with increase in the educational status of the mother. There was $4 \%$ colostrum discard. Prelacteals were given by 11\%. $56.2 \%$ of infants less than 6 months of age were exclusively breast fed $^{2}$.

Female literacy is on the rise. Maternal education has a deep impact on the feeding practice ${ }^{3} \mathrm{In}$ Kerala as per 2001 census female literacy was $90.86^{5}$ and 2011 census showed a further increase to $93.91 \%{ }^{3}$. Continuous vigilance over infant feeding practices in the community is necessary for timely interventions, to ensure optimal growth and development. This information will be useful to policy makers for the formulation of interventional programs in the future ${ }^{4}$.As there were no previous studies regarding infant feeding practices in this area we felt the need to conduct the present study. In this study conducted at a tertiary care centre in North Kerala we also evaluated association between educational status and religion with the feeding practice.

\section{METHODS}

This study was cross-sectional descriptive in design. Mothers accompanying healthy full term infants (1 year and below) attending well baby clinic of a tertiary hospital for immunisation and check up, in a time interval of 6 months constituted the study subjects. The protocol was approved by the ethical committee. Informed consent was taken from the mothers.

Mothers were interviewed using a pretested interview schedule which collected information regarding

Knowledge of the mother regarding infant feeding practices like time of first feed, type of first feed, prelacteals, colostrum feeding, schedule of feeding, supplementary feeding and complementary feeding were collected.

Practice presently followed regarding the above.

For the purpose of classification of educational status, mothers were grouped into Professionals, Plus two and above educated, S.S.L.C pass and primary educated.

All feeding practices presently followed were based on 24 hour recall. For time of initiation of first feed, type of first feed, prelacteals, colostrum feeding historic recall was used. After completion of the data collection it was entered in Microsoft Excel. Data analysis was done using SPSS version 10. Qualitative variables were summarised as frequency and percentage. Association between demographic and other variables with the feeding practice was tested using Chi- square test. A value of 0.05 or less was considered as statistically significant.

\section{RESULTS}

A total of 432 mothers and their infants were enrolled in the study.

$44 \%$ of the mothers were in the S.S.L.C completed group and constituted the majority, Mothers who were plus two and above educated, primary school completed, professionals constituted 33\%, 20\% and 3\% respectively. Hindus were $46 \%$, Christians $31 \%$ and Muslims 
$23 \%$ respectively. Majority of the babies were in the age group 3-4 months

\section{Awareness}

Majority of mothers wanted to give breast milk (83\%) as the first feed, within 1 hour of birth (94\%), and desired to feed on demand (97\%). Majority of mothers wanted to start complementary feeding before the age of 6 months (70\%). $4.6 \%$ of the mothers felt that artificial feeds were needed.

When the educational status of the mothers was taken into account $100 \%$ of the professionals, $97 \%$ of the Plus two and above, $85 \%$ of SSLC completed and $52 \%$ of the primary educated wanted to give breast milk as the first feed. The analysis shows $\mathrm{p}<0.001$ showing an association between educational status and type of first feed. $100 \%$ of the professionals, $99 \%$ of plus two and above educated, $95 \%$ of S.S.L.C completed and $83 \%$ of the primary educated favoured feeding within 1 hour of birth. Similarly maternal educational status was found to have an association with time of first feed. $(\mathrm{p}<0.001)$. No association was found between awareness regarding schedule of feed and educational status. Awareness regarding need for artificial feeds also was found to have a statistically significant relation $(\mathrm{p}<0.001)$ with educational status. $14 \%$ of the professionals, $48 \%$ of plus two and above educated, $90 \%$ of SSLC completed and $77 \%$ of primary educated wanted to give complementary feeding to their babies before the age of 6 months. Maternal education was statistically significant in relation to awareness of age of initiation of complementary feeding $(\mathrm{p}<0.001) 39 \%$ of the Muslims were of the opinion that "Zam Zam" water had to be given as the first feed. "Zam Zam" is holy water brought from Mecca. The analysis provided a $\mathrm{p}$ value of $\quad<0.001$ showing a significant association between religion and type of first feed. Similarly analysis showed an association between religion and time of first feed.( $p=0.001)$. $96 \%$ of the Hindus, $98 \%$ of the Christians and Muslims wanted to feed on demand. No relation between religion and schedule was found on analysis. $(\mathrm{p}=0.502)$. There is no significant association between religion and need for artificial feeds. $(\mathrm{p}=0.404) 78 \%$ of Hindus, $79 \%$ of Christians and $42 \%$ of Muslims wanted to wean their babies before 6 months of age. Analysis showed $\mathrm{p}<0.001$ showed a significant association between awareness of age of weaning and religion.

\section{Practice}

In the present study there was no colostrum discard. $7.5 \%$ of mothers gave the first feed after 1 hour Majority of the mothers gave breast $\operatorname{milk}(80.2 \%)$ as the first feed within 1 hour of life $(92.5 \%)$ and were feeding their babies on demand( $97 \%) .9 .7 \%$ of the mothers gave holy water as the first feed Artificial feeds were given by $14.8 \%$ of the mothers.

$89 \%$ of Hindus, $90.4 \%$ of Christians and $48.6 \%$ of Muslims gave breast milk as the first feed. Glucose water was given by $9 \%$ of Muslims and $6 \%$ of Hindus. Holy water was given by $42.4 \%$ of Muslims. On analysis a $\mathrm{p}<0.001$ showing an association between religion and first feed given. Similarly analysis provided a $\mathrm{p}=0.002$ showing a association between religion and time of first feed, $96 \%$ of the Hindus started breast feeds within 1 hour of delivery.

$13.7 \%$ Hindus, $18.4 \%$ Christians and $12 \%$ of Muslims gave artificial feeds. On analysis $\mathrm{p}=0.344$ was got showing no association between religion and artificial feeding. Similarly no association was found between schedule of feeding and religion $(\mathrm{p}=0.502)$. In infants $<6$ months $13.8 \%$ were started on complementary feeds. $23.4 \%$ of the Christians $17 \%$ of the Muslims and $1.8 \%$ of the Hindus had started their babies on complementary feeds which was found to be statistically significant $\mathrm{p}<0.001$. No association was found between early introduction of complementary feeding and educational status. Among infants above the age of 6 months statistical significance was got with religion where $62.3 \%$ of Hindus, $100 \%$ of Christians and $76 \%$ of 
the Muslims had started complementary feeding. early. $(\mathrm{p}=0.023)$

\section{Exclusive breast feeding}

In the study 288 babies were below 6 months of age of which $28 \%$ were not exclusively breast fed. $14.2 \%$ were started on artificial feeds and $13.8 \%$ were on complementary feeds.

23.4\% of the Christians $17 \%$ of the Muslims and $1.8 \%$ of the Hindus had started their babies on complementary feeds which was found to be statistically significant $\mathrm{p}<0.001$. No association was found between early introduction of complementary feeding and educational status.

$16 \%$ of Hindus $34 \%$ of Christians $39.6 \%$ of Muslims did not practice exclusive breast feeding. Analysis showed a p value $<0.001$ showing relation between religion and practice of exclusive breast feeding.

Exclusive breast feeding was practiced by $25 \%$ of the professionals, $66 \%$ of plus two and above educated, $69.4 \%$ of SSLC pass and $90.7 \%$ of the primary educated. Analysis showed it was statistically significant.

\section{Complementary feeding}

97.9\% of the babies above the age of 6 months were on complementary feeds, however early initiation of complementary feeds were found in $71.6 \%$. Statistically significant relation was found between maternal education and age of starting complementary feeds. (Table 1)

\section{DISCUSSION}

It was found in the present study that $83 \%$ of the mothers were aware that breast feed ought to be the first feed but the same was followed by $80.2 \%$ only. Similarly a drop in percentage was noted regarding the time of initiation of breast feeds within 1 hour. Kumar et al in an Allahabad anganawadi study found that though $71 \%$ of the mothers were aware about giving breast milk as the first feed only $24 \%$ gave it. A gap between awareness and practice about the type and time of first feed was obtained ${ }^{5}$.
$92.5 \%$ of the mothers in the present study initiated breast feeding within one hour which was similar to a study done in Andhra , where 82.2\% had initiation within one hour ${ }^{6}$. A study done in Kolkata where $76.6 \%$ initiated within 24 hours $^{7}$ which was much more than the NFHS 3 survey $^{2}$. The reason of high rate of breast feed initiation as compared to other studies is that it is a hospital based study, all the babies were hospital delivered and motivated by the hospital staff. Moreover all the mothers were literate.

A relation between religion, level of education of mother and time of first feed was got in this study. Initiation within 1 hour was more in mothers with more education. In Bhavnagar improved rates with early initiation within one hour was found in the literate when compared with the illiterate ${ }^{8}$. NFHS-3 survey ${ }^{2}$ and a study from Kalamboli also replicated similar findings ${ }^{9}$.

In spite of all the mothers being educated $19.8 \%$ gave prelacteals, the substances being holy water, glucose and water. The practice of giving prelacteals was more in mothers with less education.

This is similar to the NFHS-3 Kerala where prelacteals administration was $10.8 \%$. A study from Andhra showed $13 \%$ prelacteals $^{6}$. Meshram et al from Medak ${ }^{10}$, Ashwini et al from Belgaum ${ }^{11}$ found $45 \%$ and $57 \%$ prelacteal usage respectively. In contrast to this Sethi $\mathrm{V}^{12}$ found $80 \%$ and Anuradha et al found $96.6 \%$ prelacteals in a squatter population in Jaipur ${ }^{13}$.

A hospital study from Punjab also showed 70\% prelacteal administration ${ }^{14}$.

In the present study there was no colostrum discard. This is similar to many studies from Kalamboli $(95.1 \%)^{9}$,Sasikala et $\mathrm{al}^{6}(96.5 \%)$ and Despande et $\mathrm{al}^{15}$.

More mothers actually gave artificial feeds contrary to their belief. . Artificial feeding was more in mothers with higher education. This is similar to a study in Delhi where the use of artificial feeds and bottle was more in graduate mothers ${ }^{16}$. This may be because most of the 
professionals were employed and had to resort to early introduction of complementary feeding also. Most of the mothers were feeding on demand. Statistical significance was not got with education or religion. This similar to a study from Karnataka where $87.1 \%$ mothers were feeding on demand ${ }^{17}$. Majority of the mothers preferred demand feeding in studies by Sasikala et al $(61.7 \%){ }^{6}$ Aswini $(67.89 \%)^{11}$ Bhavana $(91 \%)^{18}$ Vyas Shali et al $(89 \%)^{19}$

Analysis showed that both awareness and ideal practices of breast feeding were more in mothers with higher educational status. Exception was exclusive breast feeding which was lower in mothers with higher educational status. In contrast Roy et al found decreased rates of exclusive breast feeding in the illiterate population ${ }^{7}$. Among babies less than 6 months old in the study only $72 \%$ were exclusively breast fed. This is similar to a study from Kalamboli where $70.2 \%$ babies were exclusively breast fed $^{9}$. Studies from Andhra showed lower rates of $19.89 \%{ }^{6}$, Lower rate were got from a study from Karnataka $(41.7 \%){ }^{17}$ Ashwini et $\mathrm{al}^{11}$, Meshram et $\mathrm{al}^{10}$ Bhavana et $\mathrm{al}^{18}$ also found lower rates of exclusive breast feeding $15.26 \%, 41.4 \%$ and $27.1 \%$ respectively. Early initiation of complementary feeding was found in babies above the age of 6 months. $70.1 \%$ of the mothers started complementary feeding before the age of 6 months in a study by Sasikala et $\mathrm{al}^{6}$

Religion also had an influence on type and time of first feed as well as complementary feeding.

\section{CONCLUSION}

Despite higher rate of early initiation of breast feeding, colostrum feeding and demand feeding, exclusive breast feeding was comparatively low. Early initiation of complementary feeding was also noted. Knowledge and practice of infant feeding varied with religion and educational status of the mother.

\section{Recommendations}

Education regarding infant feeding practices by a dedicated team should be able to drive home advantages of the same, strengthen the good and do away with the harm ones. Mothers with higher educational status were aware of the ideal infant feeding practices but could not follow it probably because of the need to return to work. Crèches and breast milk storing facilities have to be incorporated in all facilities

\section{Limitations}

The study was carried out at a well baby clinic of a tertiary hospital and it included children from health-conscious mothers, coming to the center for immunization. The sample size was not large because preterm babies were not included in the study. Hence, a small sample size and selection bias due to clinic-based nature of study limits its representativeness.

We analysed the relation of educational status of the mothers also with the feeding practice. (Table 1) 


\section{JMSCR Vol||04||Issue||06||Page 10886-10892||June}

Table 1 Infant feeding practice in relation to maternal education

\begin{tabular}{|c|c|c|c|c|c|}
\hline 1.Type of first feed & $\begin{array}{l}\begin{array}{l}\text { Professional } \\
(\mathrm{n}=14) \\
(\%)\end{array} \\
\end{array}$ & $\begin{array}{l}\text { Plus two and } \\
\text { above }(\mathrm{n}=142) \\
(\%)\end{array}$ & $\begin{array}{l}\text { S.S.L.C } \\
(\mathrm{n}=192) \\
(\%)\end{array}$ & $\begin{array}{l}\text { Primary }(\mathrm{n}=84) \\
(\%)\end{array}$ & $\mathrm{P}$ value \\
\hline Breast milk & $14(100 \%)$ & $122(86 \%)$ & $158(82 \%)$ & $52 \quad(62 \%)$ & $<0.001$ \\
\hline Glucose & 0 & $7 \quad(5 \%)$ & $11 \quad(5.7 \%)$ & $11(13 \%)$ & \\
\hline Water & 0 & $2(1 \%)$ & $\begin{array}{ll}7 \quad(4 \%) \\
\end{array}$ & $\begin{array}{ll}6 & (7 \%)\end{array}$ & \\
\hline Holy water & 0 & $11 \quad(8 \%)$ & $16 \quad(8.3 \%)$ & $15(18 \%)$ & \\
\hline \multicolumn{6}{|l|}{ 2.Time of first feed } \\
\hline Within $1 \mathrm{hr}$ & $14 \quad(100 \%)$ & $137(96 \%)$ & $183(95 \%)$ & $66 \quad(79 \%)$ & $<0.001$ \\
\hline After $1 \mathrm{hr}$ & & $5 \quad(4 \%)$ & $9 \quad(5 \%)$ & $18 \quad(21 \%)$ & \\
\hline \multicolumn{6}{|c|}{ 3.Artificial feeds given } \\
\hline Yes & $10 \quad(71.4 \%)$ & $28 \quad(20 \%)$ & $19 \quad(10 \%)$ & $7 \quad(8 \%)$ & $<0.001$ \\
\hline No & $\begin{array}{ll}4 & (28.6 \%)\end{array}$ & $114(80 \%)$ & $173 \quad(90 \%)$ & $77(92 \%)$ & \\
\hline \multicolumn{6}{|l|}{ 4..Schedule of feed } \\
\hline On demand & $14(100 \%)$ & $138 \quad(97 \%)$ & $186 \quad(97 \%)$ & $81 \quad(96 \%)$ & 0.907 \\
\hline On schedule & 0 & $4(3 \%)$ & $6 \quad(3 \%)$ & $3(4 \%)$ & \\
\hline \multicolumn{6}{|c|}{$\begin{array}{l}\text { 5.Age of starting } \\
\text { complementary feeding\# }\end{array}$} \\
\hline$<6$ months & $\begin{array}{ll}2 & (33.3 \%)\end{array}$ & $(47 \%)$ & $61 \quad(89.7 \%)$ & $14(73.6 \%)$ & $<0.001$ \\
\hline 6 months and above & $\begin{array}{ll}4 & (66.7 \%)\end{array}$ & $(53 \%)$ & $(8.8 \%)$ & $\begin{array}{ll}3 & (15.7 \%)\end{array}$ & \\
\hline
\end{tabular}

\# babies who were above 6 months of age.

Initiation of breast feeding within 1 hour was more in the Professionals. Artificial feed usage was less in the primary educated.

\section{Acknowledgements}

The authors gratefully acknowledge pediatric department A.C.M.E Pariyaram for their support in conducting the study.

\section{REFERENCES}

1. Mahmood SE, Srivastava A, Shrotriya VP, Mishra P. Infant feeding practices in the rural population of north India. Journal of Family Community Medicine 2012 MayAug; 19(2):130-135

2. International Institute for Population Sciences (IIPS), India and Macro International. National Family Health Survey (NFHS-3), 2005-6: India:Volume 1. Mumbai:IIPS;2007

3. Census 2011 http://www.censusindia. gov.in/2011-prov-results/data_files/india/ Final_PPT_2011_chapter6.pdf accessed on 1.06 .2016
4. Aggarwal A, Verma S, Faridi MMA, Dayachand. Complementary feeding Reasons for inappropriateness in timing, quantity and consistency. Indian $\mathbf{J}$ Pediatr 2008;75(1);49-53

5. Kumar D, Goel NK, Kalia M, Swami HM, Singh R. Gap between awareness and practices regarding maternal and child health among women in an urban slum community. Indian J Pediatr 2008;75(5):455-458

6. Sasikala M.K, Jyothi Conjeevaram, Chandrasekhar V, Susmitha K.M A Study on Infant Feeding Practices Among Mothers in the Rural Field Practice Area of a Teaching Hospital in South India. National $\mathbf{J}$ of research in community medicine. Oct-Dec 2015;4(4):344-348

7. Roy S, Dasgupta A, Pal B. Feeding practices of children in an urban slum of 
Kolkatta. Indian J Community Med 2009Oct;34(4):362-363

8. Raval D, Jankar DV, Singh MP. A study of breast feeding practices among infants living in slums of Bhavnagar city Gujarat, India. Healthline2011;July-Dec;2(2)

9. Kulkarni RN, Anjaneya S, Gujar R. Breast feeding practices in an urban community of Kalamboli, Navi Mumbai. Indian community Med. Oct-Dec 2004;24(4)

10. Meshram, I. I., Laxmaiah, A., Venkaiah, K., \& Brahmam, G. N. V. (2012). Impact of feeding and breastfeeding practices on the nutritional status of infants in a district of Andhra Pradesh, India. National Medical Journal of India, 25(4), 201.

11. Ashwini S, Katti SM, Mallapur MD. Comparison of breast feeding practices among urban and rural mothers. A crosssectional study. Int $\mathrm{J}$ Med Public Health 2014,4:120-4 available at http://www.ijmedph.org/text.asp?

DOI:10.4103/2230-8598.127172 accessed on 1.6.16

12. Sethi V, Kashyap S, Seth V, Effect of nutrition education of mothers in infant feeding practices, Indian J pediatr 2003; 70:463-466

13. Goyle A, Jain P, Vyas S, Saraf H, Shekhawat N. Colostrum and prelacteals feeding practices followed by families of pavement and road side squatter settlements. Indian J Prev. Soc.Med.2004;35(1\&2):58-62

14. Dhir SK,Batta M. Int J community Medicine and Public Health.2015 Nov;2(4):435-440

15. Deshpande JD, Giri PA, Phalke DB, Phalke VD, Kalakoti P, Syed MM. Sociocultural practices in relation to breastfeeding, weaning and child rearing among Indian mothers and assessment of nutritional status of children under five in rural India.AMJ.2010;3:618-24
16. Rasania SK, Singh SK, Pothi S, Bhalia S, Sachdev. Breast feeding practices in a maternal and child health centre in Delhi. Health and Population Perspectives and issues 2003;26(3):110-115

17. Joseph N, Unnikrishnan B, Naik VA, Mahantshetti N S, Mallapur M D, Kotian SM, Nelliyanil M. Infant rearing practices in south India: A longitudinal study. J Family Med Prim Care 2013;2:37-43

18. .Bhavana R.Hiremath et.al. A Crosssectional study on breast feeding practices in a rural area of NorthKarnataka.Int J Cur Res, Nov 2013/Vol 05(21),13-17.

19.. Vyas Shaili,Sharma Parul,Kandpal S D,Semwal Jayanti, Srivastava Anurag, Nautiyal Vipul. A Community based study on breastfeeding practices in a rural area of Uttarakhand.National Journal of Community Medicine Vol 3, Issue 2 Apriljune 2012 